\title{
REFLEXÕES SOBRE O CENÁRIO ECONÔMICO BRASILEIRO DA DÉCADA PERDIDA À ABERTURA COMERCIAL
}

\begin{abstract}
Resumo No início dos anos 70, seguindo o Primeiro Plano de Desenvolvimento (I PND), que consistia na ampliação dos investimentos, com o objetivo de transformar a estrutura produtiva e superar os desequilíbrios externos, o Brasil crescia a uma taxa anual de dois dígitos, em um ambiente relativamente estável. Essa estabilidade econômica, proporcionada principalmente pelas medidas adotadas no período, permitiu uma expansão industrial durante dez anos seguidos, colocando o país entre as nações industrializadas. Analisando a época, que compreende desde os choques do petróleo até meados de 1996, o objetivo deste artigo é apresentar, primeiramente por meio de dados e informações, um estudo da estagnação da economia brasileira na década de 1980. Com uma exposição detalhada dos fatores que contribuíram para essa estagnação, como o primeiro e o segundo choque do petróleo, a dívida do setor público, dívida externa e inflação. Posteriormente, busca-se relatar o impacto do processo de liberalização econômica no Brasil, observando os impactos da abertura comercial para a economia, realizando uma análise na importância e no impacto da competitividade internacional entre os países, e a influência do comércio internacional no processo de desenvolvimento brasileiro, relatando as políticas econômicas e medidas adotadas durante o governo em questão.
\end{abstract}

PALAVRAS-CHAVE: ESTAGNAÇÃO; INFLAÇÃO; ABERTURA COMERCIAL; COMPETITIVIDADE; DESENVOLVIMENTO.

ABSTRACT In the early 70s, following the I Development Plan (PND), which consisted on the expansion of investments in order to transform the productive structure and overcome external imbalances, the Brazil grew at an annual rate of two digits in a relatively stable environment. This mainly economic stability provided by the measures adopted during the period, allowed for industrial expansion for ten consecutive years, placing Brazil among the industrialized nations. Analyzing the period covered since the oil shocks until mid-1996, the purpose of this article is primarily to present through data and information an analysis of the stagnation of the Brazilian economy in the 1980 s, with a detailed analysis of the factors that contributed to this stagnation, such as the first and the second oil shock, the public sector debt, external debt and inflation. Later report the impact of the economic liberalization process in Brazil observing the impacts of trade liberalization for the economy performing an analysis on the importance and impact of the international competitiveness between countries, and the influence of international trade in the Brazilian development process, reporting policies and economic measures adopted during the government concerned.

KEY-WORDS: STAGNATION; INFLATION; TRADE LIBERALIZATION; COMPETITIVENESS; DEVELOPMENT.

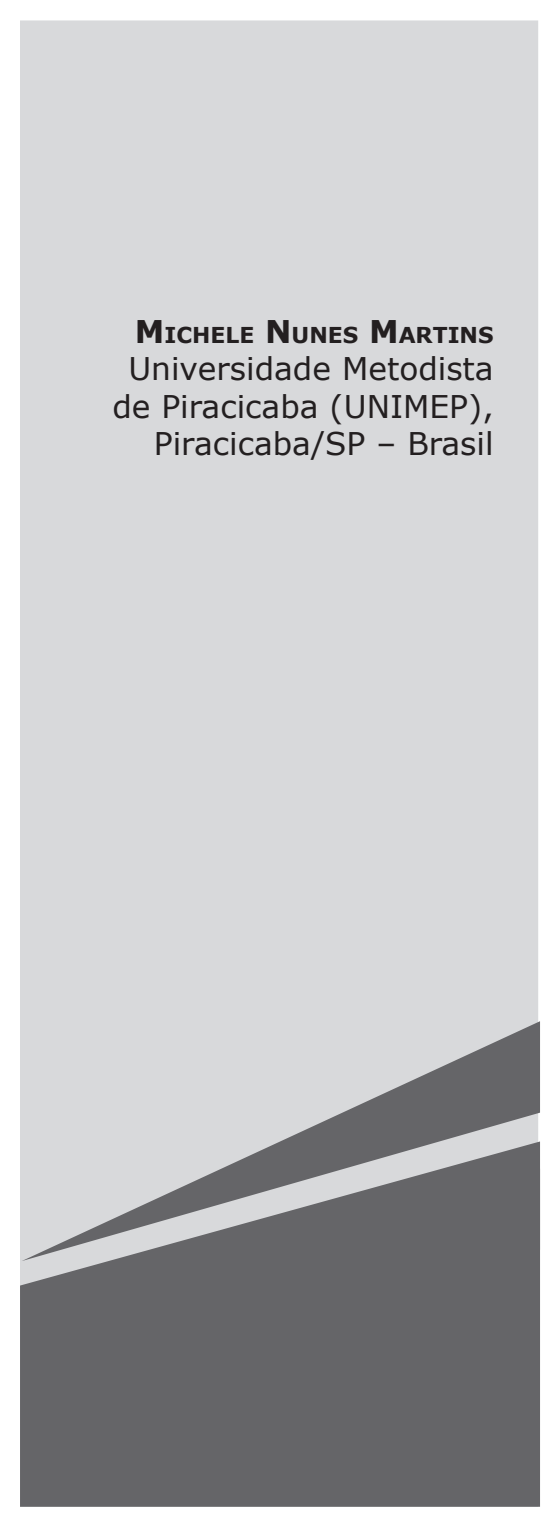




\section{INTRODUÇÃO}

$\mathrm{O}$ percurso trilhado pela economia brasileira evidencia um elevado dinamismo ao longo do período entre 1930 até 1980 , de industrialização com taxas médias de crescimento de $6 \%$ ao ano. Segundo Carneiro (2002), a interação entre crescimento do produto e produtividade permitiu o aumento dos lucros e salários, ampliando, assim, suas fontes de dinamismo. A redução da taxa de crescimento a partir de $1980 \mathrm{fez}$ que o Brasil perdesse as características que permitiram esse dinamismo.

Os choques dos preços do petróleo entre 1973-1974 repercutiram posteriormente em sérios impactos na economia brasileira, causando uma série de dificuldades e apertos para o país. Os aumentos dos preços dos produtos nos mercados mundiais, com a ele- vação do preço do petróleo, fizeram o saldo comercial retroceder logo após ter atingido o seu ponto máximo. A partir de 1980 , os preços das commodities exportadas pelo Brasil despencaram, chegando a cair $26 \%$ de 1980 a 1982. Essas quedas dos preços evidenciavam que o problema da balança comercial não estava centrado apenas no petróleo. As políticas adotadas no período agravaram a situação brasileira nos mercados mundiais. Com o aumento da vulnerabilidade da economia brasileira, a aceleração da inflação acabou sendo consequência do resultado da conjunção dos fatores mencionados, além da desaceleração dos investimentos privados. O aumento dos preços internos elevou ainda mais os níveis da inflação. A aceleração inflacionária a partir de 1979 foi inevitável devido ao aumento dos preços internos, pressionados pelo mercado externo (BAER, 1996).

Tabela 1 - Taxa de Inflação (IGP \%) 1974-1982

\begin{tabular}{l|l|l|l|l|l|l|l|l|l|l}
\hline Ano & 1973 & 1974 & $\mathbf{1 9 7 5}$ & $\mathbf{1 9 7 6}$ & $\mathbf{1 9 7 7}$ & $\mathbf{1 9 7 8}$ & $\mathbf{1 9 7 9}$ & $\mathbf{1 9 8 0}$ & $\mathbf{1 9 8 1}$ & $\mathbf{1 9 8 2}$ \\
\hline IGP & 16,2 & 33,8 & 30,1 & 48,2 & 38,6 & 40,5 & 76,8 & 110,2 & 95,2 & 99,7 \\
\hline
\end{tabular}

Fonte: Baer (1987, p.30).

Tabela 2 - Taxas de Crescimento (1974-1982)

\begin{tabular}{l|l|l|l}
\hline Período & PIB & Indústria & Agricultura \\
\hline 1973 & 13,6 & 16,3 & 3,6 \\
\hline 1974 & 9,7 & 9,2 & 8,2 \\
\hline 1975 & 5,4 & 5,9 & 4,8 \\
\hline 1976 & 9,7 & 12,4 & 2,9 \\
\hline 1977 & 5,7 & 3,9 & 11,8 \\
\hline 1978 & 5,0 & 7,2 & $-2,6$ \\
\hline 1979 & 6,4 & 6,4 & 5,0 \\
\hline 1980 & 7,2 & 7,9 & 6,3 \\
\hline 1981 & $-1,6$ & $-5,5$ & 6,4 \\
\hline 1982 & 0,9 & 0,6 & $-2,5$ \\
\hline
\end{tabular}

Fonte: $\operatorname{Baer}(1987$, p.30).

O Brasil passou por uma série de problemas na década de 1980 , oriundos das políticas desenvolvimentistas adotadas pelo Governo no período anterior. Os principais problemas enfrentados que podem ser destacados foram a aceleração inflacionária, o elevado grau de endividamento externo, o déficit no balanço de pagamentos e o elevado endividamento do setor público.

A década de 1990 ficou marcada pela implantação de políticas de liberalização, visando estabelecer, segundo Carneiro (2002), 
um padrão de crescimento centrado em uma nova inserção internacional e na redefinição do papel do Estado, tendo como resultados a tão almejada estabilidade inflacionária, porém com baixo dinamismo da economia. $\mathrm{A}$ introdução do Plano Real utilizou políticas diferentes de todas as adotadas, e que fracassaram no combate à inflação. A estratégia de desenvolvimento do Plano Real tinha como pressupostos básicos: a estabilidade de preços; a abertura comercial e valorização cambial; as privatizações e a liberalização cambial.

\section{DÍVIDA EXTERNA - ORIGEM E CONSEQUÊNCIAS}

Em 1974, diante do Primeiro Choque do Petróleo, o governo brasileiro adotou medidas de uma política de crescimento que resultou em importantes mudanças estruturais na economia, no ressurgimento acelerado da inflação e na expansão da dívida externa. Os anos 1968-1973, sob o governo do general Emilio Médici foram marcados pelo crescimento da economia que ficaram conhecidos como "milagre econômico", devido ao rápido e excepcional crescimento econômico pelo qual passou o Brasil. As taxas de crescimento do Produto Interno Bruto (PIB) chegaram à média de $11,1 \%$ ao ano, em contrapartida, a taxa de inflação declinou de $45,4 \%$ para $19,1 \%$, além da constatação da forte aceleração na taxa de crescimento das exportações e importações no período 1968-1973. Como resultado, o aumento das desigualdades sociais e a dívida externa são as principais características herdadas do período. Embora a economia tenha crescido consideravelmente, ficou evidente o aumento das desigualdades sociais devido ao aumento da concentração de renda. O desenvolvimento econômico, "bancado" principalmente com empréstimos externos, causou o aumento da dívida externa, prejudicando o Brasil nos anos futuros, como será analisado a seguir. À custa do endividamento, o Brasil conseguiu isolar-se da inflação importada e assegurar uma taxa significativa de crescimento do investimento (CARNEIRO, 2002).
No ano de 1974, o período de crescimento da economia brasileira chegara ao fim, com a crise mundial provocada pelo "Choque do Petróleo". O elevado aumento nos preços do petróleo no mercado mundial afetou a economia brasileira, por conseguinte, elevando a inflação. A balança comercial brasileira apresentou grande déficit em função da importação de petróleo a preços altos, além da queda nos investimentos externos e internos. Entre os anos de 1974 e 1979, o PIB brasileiro passou a crescer à média de $6,5 \%$, diminuindo a geração de empregos e a massa salarial, como resultado obteve-se a diminuição do consumo interno afetando as empresas nacionais e causando a desaceleração no processo de crescimento da economia brasileira. O "Milagre Econômico" permaneceu apenas enquanto as condições internacionais eram favoráveis. Os choques externos tiveram contribuição importante para a queda na taxa de crescimento.

Em 1979, surge então o segundo choque do petróleo, complicando o cenário, contribuindo para a diminuição brusca das exportações. A elevação das taxas de juros mundiais acarretou no aumento do serviço da dívida do país. ${ }^{1}$

Um dos principais fatores do problema brasileiro na "década perdida" foi o agravamento da crise que se deveu primordialmente à inflação crescente afetando e piorando o custo de vida da classe trabalhadora. As políticas adotadas pelo governo como a contenção dos salários que não acompanhavam a inflação geraram profundo descontentamento da classe trabalhadora com o Governo. Alguns autores atribuem parte do "milagre econômico" às reformas econômicas implementadas no Governo de Castelo Branco, com as reformas do PAEG (Plano de Ação Econômica do Governo), que criaram condições para a aceleração do crescimento entre 1968-1973. Posteriormente,

Baer refere-se a uma maior desvalorização que naturalmente aumentaria as pressões inflacionárias e elevaria significativamente a carga financeira sobre as empresas que tinham dívidas no exterior (BAER, 1996, p.112). 
em 1974, as políticas econômicas severas adotadas e o ambiente externo contribuíram para a queda na taxa de crescimento.

O déficit comercial e os juros elevados conduziram o país para um extraordinário aumento da dívida externa. Conforme análise da Tabela 3, a dívida externa (bruta) saltou de US\$3,3 bilhões, em 1964, para US\$ 49 bilhões em 1979.

Tabela 3 - Indicadores sobre a Dívida Externa

\begin{tabular}{l|l|l|l|l|l}
\hline Ano & $\begin{array}{l}\text { Taxa de Juros } \\
\text { Prime rate (\%) }\end{array}$ & Juros sobre a dívida* & $\begin{array}{l}\text { Dívida } \\
\text { bruta }\end{array}$ & Reserva & $\begin{array}{l}\text { Crescimento do } \\
\text { PIB (\%) }\end{array}$ \\
\hline 1964 & 4,5 & $-0,13$ & 3,3 & 0,2 & \\
\hline 1965 & 4,5 & $-0,16$ & 3,8 & 0,5 & 2,3 \\
\hline 1966 & 5,6 & $-0,16$ & 3,8 & 0,4 & 6,3 \\
\hline 1967 & 5,6 & $-0,18$ & 3,4 & 0,2 & 4,0 \\
\hline 1968 & 6,3 & $-0,14$ & 4,1 & 0,2 & 8,9 \\
\hline 1969 & 8,0 & $-0,18$ & 4,6 & 0,6 & 8,7 \\
\hline 1970 & 7,9 & $-0,23$ & 6,2 & 1,2 & 9,4 \\
\hline 1971 & 5,7 & $-0,3$ & 8,3 & 1,7 & 10,2 \\
\hline 1972 & 5,3 & $-0,36$ & 11,5 & 4,2 & 10,7 \\
\hline 1973 & 8,2 & $-0,51$ & 14,9 & 6,4 & 12,3 \\
\hline 1974 & 10,8 & $-0,65$ & 20,0 & 5,3 & 7,5 \\
\hline 1975 & 7,8 & $-1,5$ & 25,1 & 4 & 4,9 \\
\hline 1976 & 6,8 & $-1,8$ & 32,1 & 6,5 & 9,3 \\
\hline 1977 & 6,9 & $-2,1$ & 38,0 & 7,2 & 4,7 \\
\hline 1978 & 9,2 & $-2,7$ & 52,2 & 11,9 & 4,7 \\
\hline 1979 & 12,7 & $-4,2$ & 55,8 & 9,7 & 6,3 \\
\hline
\end{tabular}

Fonte: Banco Central e Ipeadata. Em US\$ bilhões.

Com o crescimento da dívida externa em razão das políticas desenvolvimentistas de crescimento econômico adotadas no período anterior, o II PND (Segundo Plano Nacional de Desenvolvimento Econômico) é implantado entre 1975-1979 pelo Governo Geisel com o objetivo fundamental da consolidação do processo de substituição de Importações, e por conseguinte solucionar o problema da dependência externa. Para isso, o plano comportava uma série de investimentos nos setores de bens de capital e bens intermediários. Resultados concretos do II PND só puderam ser visualizados a partir de 1983-1984, podendo ser destacadas a reversão no saldo da ba- lança comercial que se tornou superavitária, uma menor dependência das importações do petróleo e uma maior diversificação na pauta de exportação do país (BAER, 1996).

A dependência externa do Brasil agravou-se ainda mais com o Segundo Choque do petróleo, em 1979, e com o aumento das taxas de juros internacionais. O dilema no período era de controlar a inflação crescente e conter a dívida externa, cujos juros e amortização corroíam boa parte dos ganhos com as exportações. Já naquele período, a economia brasileira dava indícios de estagnação da taxa de crescimento do PIB. A dívida externa do Brasil ultrapassou US\$100 bilhões, levando o 
país a solicitar auxílio ao FMI (Fundo Monetário Internacional) em 1982. As relações de troca da economia brasileira encontravam-se fortemente fragilizadas devido à queda dos preços de outros bens primários exportados. O peso acarretado pela dívida externa afetou as finanças públicas, colaborando com a elevação da inflação.

No início dos anos 80, o Brasil foi "obrigado" a adotar ajustes econômicos severos, que resultaram em uma taxa de crescimento negativa. A capacidade de investimento do país estava danificada com o corte de ingresso de capital estrangeiro. A adoção de medidas com o objetivo de estabilização monetária marcou o fim da política de contenção, ajustes salariais e congelamento de preços. As suspensões de pagamentos dos juros da dívida por parte do Governo não surtiram efeito, mesmo assim a produção econômica continuava a crescer até o final da década de 80 , proporcionando excedente na balança comercial, suficiente para cobrir o serviço da dívida.

O período dos anos 1980 ficou conhecido como a "década perdida", caracterizada principalmente pela queda nos investimentos e no crescimento do PIB, pelo aumento do déficit público, pelo crescimento da dívida externa e interna e pela elevação inflacionária.

\section{A CRISE DA DÉCADA DE 1980}

O ano de 1980 marca o fim de um modelo de desenvolvimento ancorado em investimento estatal e financiamento externo. A década de 80 é considerada a "década perdida" da economia brasileira, caracterizada por um período de estagnação, em um cenário marcado pelos baixos níveis de crescimento do PIB, com o crescimento médio de apenas $2 \%$, um agravante aumento do déficit público devido ao crescimento desordenado da dívida externa de curto prazo em razão da elevação das taxas internacionais de juros, conduzindo as reservas líquidas do Banco Central do Brasil a níveis negativos, indicando a incapacidade do país em lidar com a posterior crise de liquidez. O resultado do período analisado é considerado medíocre, a desaceleração re- presentou uma queda nas médias históricas de crescimento dos cinquenta anos anteriores. Em meados da década de 1980, as tentativas de retomar o crescimento econômico e melhorar a distribuição de renda tropeçaram na restrição externa.

As medidas fiscais e monetárias adotadas a partir de 1981, com objetivos de diminuição da dívida externa e "estabilização econômica”, resultaram na diminuição brusca da atividade interna, impactando diretamente na queda da atividade industrial. Em 1981, o país entrou em recessão devido à política severa adotada pelo Governo, de contenção dos gastos e diminuição das importações. A recessão durou até o segundo semestre de 1982, quando ocorreu a moratória mexicana, impactando diretamente na queda do fluxo de financiamento externo, levando posteriormente o Brasil a buscar "auxílio" com o FMI (Fundo Monetário Internacional). O Brasil passou por uma fase de persistente instabilidade monetária e cambial, em um mesmo período em que ocorria a rápida redução dos investimentos internacionais (CARNEIRO, 2002).

As políticas adotadas a partir de então visavam à diminuição da dependência do financiamento externo e à promoção das atividades exportadoras.

Em 1983 e 1984, sob o auxílio do FMI, o Brasil adota uma política de reajuste recessivo. Uma nova desvalorização da moeda, promovida em 1983, provocou o agravamento e aumento das contas públicas com a ascensão da inflação. Baer (1996) relata o aumento do desempenho das exportações e a queda das importações que contribuíram para um resultado positivo do PIB brasileiro de $4,5 \%$, em 1984, que se ampliou, em 1985, com uma taxa de $8,3 \%$. As políticas que levaram a superávits e permitiram o pagamento dos juros da dívida externa provocaram a elevação das pressões inflacionárias e a latente queda dos investimentos, ocorridas em razão da contínua desvalorização cambial e da necessidade de se extrair uma quantidade de recursos privados maior, com a finalidade de se prosseguir o pagamento dos juros da dívida externa. 
Segundo Carneiro (2002), os anos 80 podem ser caracterizados como um período de estagnação, conforme análise dos dados da Tabela 4. Após o esgotamento da crescente expansão na época anterior, na década de 70, a economia não conseguiu implantar um novo padrão de crescimento sustentado. A instabilidade econômica no período era caracterizada por breves períodos de expansão e retração. ${ }^{2}$

Tabela 4 - Taxa de crescimento das principais variáveis econômicas (\% a.a.) 1981-1989

\begin{tabular}{l|l|l|l|l|l|l}
\hline Períodos & PIB & Consumo & FBCF & Exportação & Importação & $\begin{array}{l}\text { Memo: Saldo \% } \\
\text { do PIB }\end{array}$ \\
\hline $1981-89$ & 2,2 & 1,8 & $-1,4$ & 8,5 & $-1,3$ & 4,8 \\
\hline $1981-83$ & $-2,1$ & $-2,2$ & $-11,7$ & 8,0 & $-12,0$ & 2,6 \\
\hline $1984-86$ & 7,0 & 6,4 & 11,2 & 5,3 & 7,7 & 4,9 \\
\hline $1987-89$ & 2,1 & 1,3 & $-2,2$ & 12,3 & 1,5 & 6,7 \\
\hline $\begin{array}{c}\text { Intervalo } \\
\text { de Variação } \\
\text { (\% a.a.) }\end{array}$ & $(-4,0)$ & $(-5,7)$ & $(-16,3)$ & $(-10,6)$ & $(-7,4)$ & \\
\hline & $\mathrm{a}$ & $\mathrm{A}$ & $\mathrm{A}$ & $\mathrm{A}$ & $\mathrm{A}$ & \\
\hline & 8,3 & 9,7 & 22,2 & 21,3 & 28,6 & \\
\hline
\end{tabular}

Fonte: Carneiro (2002, p. 146).

As experiências frustradas de ajuste externo do período refletiam uma característica do desequilíbrio externo brasileiro ancorado no ajuste recessivo. Diante dos problemas que a economia brasileira enfrentava, como a dívida externa, inflação, endividamento do setor público, pressões exercidas por parte da população e dos trabalhadores, foi adotada uma série de planos econômicos para tentar conter os efeitos desses problemas.

O Plano Cruzado, introduzido sob o Governo do Presidente José Sarney em 1986, em meio a um cenário de inflação altíssima e baixos níveis de reservas internacionais, foi um dos, e se não o principal Plano adotado no período. Com a Introdução do Plano Cruzado, em 1986, com o objetivo de conter a inflação, porém sem sucesso, o Governo conseguiu apenas baixá-la para $62 \%$ ao ano. Posteriormente, com a adoção de diversos planos eco- nômicos de contenção, em 1989 com a inflação em $1.764 \%$ ao ano, a situação do Brasil já caracterizava-se como hiperinflação, chegando em abril de 1990 ao patamar máximo de 6.584\%, conforme Baer (1996).

O Plano Cruzado tentou controlar a inflação de uma maneira heterodoxa, adotando alguns princípios, como a criação de uma nova moeda, a eliminação da indexação, o congelamento de preços públicos e privados e a fixação da taxa de câmbio. Com a introdução do Plano Cruzado, a inflação recuou rapidamente, devido ao congelamento de preços e à desindexação da economia. No início de 1987, com o fim do congelamento dos preços, a inflação volta a acelerar. Alguns autores atribuem como causa da retomada da inflação o retorno rápido e significativo da liquidez ao mercado, levando as empresas a praticar as mesmas políticas de preços anteriores à reforma.

Carneiro esclarece que, no período recessivo, quando o investimento se retrai, ocorre uma redução proporcional das importações e uma aceleração do crescimento das exportações. Na retomada do crescimento interno, quando o investimento volta a crescer, ampliam-se as importações e cai a taxa de crescimento das exportações (CARNEIRO, 2002, p. 146). 
Nos anos subsequentes ocorreram outras tentativas de estabilização da inflação, com a implantação de planos como o Plano Bresser, e o Plano Verão, mas nenhum deles obteve sucesso com a adoção de medidas como prefixações, congelamentos parciais e confisco de ativos financeiros. No início, as taxas de inflação cediam, mas a elevação dos preços era constante, a competitividade da moeda cada vez mais reduzida fazia que as funções da moeda se deteriorassem e cada vez conduzindo os planos econômicos adotados ao fracasso.

A década de 80 ficou marcada por uma série de fatores, que permitem caracterizá-la como "década perdida". Os fatores mencionados que podem ser destacados como condicionantes do período foram: A elevada dívida externa, o fracasso dos programas de estabilização no combate à inflação e o esgotamento de um modelo desenvolvimentista com base na intervenção do Estado na economia. A Intervenção do Estado no período baseou-se por meio de medidas de reestruturação para gerar superávit. O papel do Governo, como principal patrocinador dos encargos da reestruturação nos anos 70, culminou com a "hiperinflação" e a necessidade de adoção de medidas e programas severos de restrição nos períodos posteriores.
Tabela 5 - Inflação no Brasil - Índice Geral de Preços (IGP)

\begin{tabular}{c|c}
\hline Período & Variação (\%) \\
\hline 1978 & 40,8 \\
\hline 1979 & 77,2 \\
\hline 1980 & 110,2 \\
\hline 1981 & 95,2 \\
\hline 1982 & 99,7 \\
\hline 1983 & 211,0 \\
\hline 1984 & 223,8 \\
\hline 1985 & 235,1 \\
\hline 1986 & 53,5 \\
\hline 1987 & 416,0 \\
\hline
\end{tabular}

Fonte: $\operatorname{Baer}(1987$, p.30)

[...] O esquema montado pelo Plano baseava-se na neutralização do fator inercial de inflação, associada ao congelamento dos preços e salários. O fator inercial provinha da correção monetária aplicada as transações financeiras e comerciais [...] Com o fim da indexação esperava-se romper a rigidez a retração inflacionária (AVERBUG, 2005, p. 220).

Instantaneamente o Plano Cruzado trouxe resultados ao Governo, conforme mostram os dados na Tabela 6, a inflação retrocedeu no mês subsequente à adoção do plano, caindo de $22,4 \%$ em fevereiro para $5,5 \%$ em março.

Tabela 6 - Inflação no Brasil - Índice Geral de Preços (IGP) Mensal

\begin{tabular}{l|l|l|l|l}
\hline Período & $\begin{array}{l}\text { Variação } \\
(\%)\end{array}$ & & Período & Variação (\%) \\
\hline 1986 & 17,8 & & 1987 & \\
\hline Jan. & 22,4 & & Jan. & 12,0 \\
\hline Fev. & 5,5 & & Fev. & 14,1 \\
\hline Mar. & $-0,6$ & & Mar. & 15,0 \\
\hline Abr. & 0,3 & & Abr. & 20,1 \\
\hline Mai. & 0,5 & & Mai. & 27,6 \\
\hline Jun. & 0,6 & & Jun. & 25,9 \\
\hline Jul. & 1,3 & & Jul. & 9,3 \\
\hline Ago. & 1,1 & & Ago. & 4,5 \\
\hline Set. & 1,4 & & Set. & 8,0 \\
\hline Out. & 2,5 & & Out. & 11,2 \\
\hline Nov. & 7,6 & & Nov. & 15,5 \\
\hline Dez. & & Dez. & 15,9 \\
\hline
\end{tabular}

Fonte: Averbug (2005, p.219). 
Segundo Carneiro (2002), o fracasso do Plano Cruzado inicia uma nova etapa no processo inflacionário, pois ocorre instabilidade dos preços procedente do ajuste externo e agravada pelo Plano, somando-se às novas expectativas de congelamento de preços. A partir de então, a aceleração da inflação é quase contínua, sendo esporadicamente contida por planos heterodoxos como Bresser e Verão, que incluíam o congelamento de preços. Conforme Belluzzo \& Almeida (1990), esse processo de aceleração quase contínua da inflação deu origem à "financeirização dos preços", ou seja, à utilização das taxas de juros de curtíssimo prazo como critério no reajuste de preços. O percurso da inflação passou assim a depender exclusivamente do movimento das taxas de juros de curto prazo. Ainda, de acordo com Carneiro (2002), os elementos que caracterizavam a hiperinflação estavam claramente demonstrados na:

[...] financeirização dos preços, na polarização da riqueza financeira nas quase-moedas ou na moeda indexada... além de supor uma continua aceleração dos preços, obscurece a noção de preços relativos e as suas relações com custos de produção (CARNEIRO, 2002, p. 218).

O Plano Collor, adotado posteriormente em 1990, por Fernando Collor de Mello, foi uma tentativa de reverter esse cenário. Tendo como principal medida o bloqueio dos ativos financeiros em circulação na economia. Tanto o Plano Collor I como o Plano Collor II implicaram na retração da atividade econômica como resultado direto das medidas fiscais e monetárias adotadas.

O Plano Collor I exerceu um forte impacto recessivo sobre a economia devido ao extraordinário declínio no estoque de ativos líquidos. A reaceleração da inflação no cenário fez que o Governo adotasse um novo plano de estabilização, o Plano Collor II, em 1991, que teve como medida principal o congela- mento dos preços e salários, além de outras medidas de aperto fiscal.

A reforma monetária obteve capacidade de restaurar principalmente algumas das funções da moeda nacional, no entanto, não conseguiu cortar pela raiz a alta inflação, mas logrou conter a hiperinflação, resultado da contenção de liquidez. No período em questão, conclui Carneiro (2002), a economia brasileira passou por uma das maiores recessões da história contemporânea, com queda de quase $10 \%$ do PIB, devido às tentativas de se controlar a inflação com o processo de reestruturação, o que causou um aumento do desemprego, queda dos salários reais e da massa de salário. Em outubro de 1992, foi determinado o impeachment de Collor, devido às denúncias por corrupção, além da truculência dos Planos Collor I e II.

\section{ABERTURA COMERCIAL - OS IMPACTOS DA LIBERALIZAÇÃO COMERCIAL}

O Brasil ensaiou um projeto de abertura de sua economia em 1964, porém sem sucesso, devido às dificuldades no balanço de pagamentos. Em 1988, o Brasil deu início a uma reforma comercial com a eliminação dos controles quantitativos e administrativos sobre as importações, além de uma proposta de redução tarifária. Ao longo dos anos 90, a economia brasileira passou por um processo intenso de liberalização. Com o governo de Fernando Collor de Mello, a abertura intensificou-se. Diferentemente das políticas adotadas anteriormente no II PND, de incentivo à substituição de importações, a nova política tinha como objetivo a questão principal da competitividade, com o aumento da eficiência na produção e comercialização de bens e serviços por meio da modernização e reestruturação da indústria.

A abertura comercial e as privatizações tiveram impacto significativo no campo produtivo da economia brasileira. Segundo Carneiro (2002), tais medidas constituíam um padrão de crescimento inverso ao adotado (desenvolvimentismo), que tinha por base a forte inter- 
venção do Estado e a industrialização por meio da substituição de importações. Esse novo modelo de crescimento tinha a ampliação da concorrência como veículo principal do processo. A redução das tarifas e a eliminação das proteções não tarifárias permitiu a entrada de novos produtores no mercado. Ampliando a concorrência nos mercados domésticos, supunha-se que essa concorrência provocaria uma reestruturação da estrutura produtiva, posteriormente implicando na modernização e recuperação do atraso tecnológico nos mercados brasileiros. A abertura comercial, além de submeter a indústria nacional a uma maior concorrência, permitiria o acesso aos mercados externos, por conseguinte, aumentando a produtividade e ampliando a competitividade. O Processo de liberalização e abertura econômica exigiu das empresas nacionais um drástico processo de ajuste para "sobreviver" à nova realidade. Como consequência da instabilidade econômica brasileira durante os anos 80 , diversos setores da economia brasileira encontravam-se em atraso tecnológico, se comparado aos padrões internacionais: "[...] O Atraso ocorria tanto na obsolescência das maquinas e equipamentos quanto nos métodos administrativo-gerenciais e nas relações capital-trabalho". ${ }^{3}$

Os métodos e as mudanças nas políticas econômicas implicados pela abertura comercial logo de cara se mostraram prejudiciais à competitividade brasileira. Os produtores locais foram severamente prejudicados com os juros elevados, tributação, carência de infraestrutura e excessiva burocracia no mercado brasileiro. Para a maioria das empresas brasileiras de menor porte, ocorre um baixo nível de produtividade, que reflete em elevados custos de produção, limitando assim sua capacidade competitiva.

A recessão provocada pela política de estabilização em vigor, com a nova política industrial, provocou um severo ajuste das empresas, envolvendo um significativo número de demissões. As demissões ocorreram não apenas dos operários de produção, mas também em áreas administrativas, caracterizan- do uma reestruturação dos processos administrativos com os objetivos de concentração em linhas de produtos competitivos, redução da diversificação da produção, terceirização de atividades e implantação de programas de qualidade e produtividade.

Como parte da reestruturação da estrutura econômica brasileira, estava a redefinição da participação do Estado por meio das privatizações. Nos anos 90, ocorre um expressivo crescimento das fusões e aquisições na economia brasileira. Para evitar que o Governo ampliasse ainda mais a sua presença no setor produtivo, as privatizações foram partes integrantes das reformas econômicas do governo. Em 1990, foi criado o PND, Programa Nacional de Desestatização. O PND promoveu até março de 1998 a transferência para o setor privado de 76 empresas. Processo esse que produziu uma receita de US\$ 37,6 bilhões.

Entre 1991 e 1992, as principais empresas privatizadas encontravam-se nos setores de siderurgia, fertilizantes e petroquímicas. Para alavancar o processo, foram introduzidas muitas mudanças na legislação. A partir de 1995, ocorreu no Brasil o maior processo de desnacionalização econômica, o impacto do PND foi ampliado com as concessões de serviços públicos à iniciativa privada (eletricidade, transportes e telecomunicações). Entre 1998 e 2001, houve várias privatizações no setor de energia e telecomunicações. No final de 2001, o PND contabilizava uma receita total oriunda das privatizações da ordem de US\$ 82 bilhões, além de US\$ 18 bilhões de transferências de dívidas. Foi destacada a crescente participação de investimento direto estrangeiro por meio do processo de privatizações, que também foi crucial para o financiamento do déficit em transações correntes do balanço de pagamentos. O déficit em contas correntes foi "financiado pela captação da poupança externa", o que proporcionou, além de estabilidade do balanço de pagamentos, o crescimento econômico, com a crescente entrada de capital estrangeiro por meio de processos de fusões ou aquisições, entre outros.

(LACERDA, 1998, p.100). 
A crescente participação do capital estrangeiro no controle da atividade produtiva é um fenômeno com sérias implicações políticas e econômicas, principalmente no que diz respeito à competitividade internacional do país. Segundo Gonçalves (2000), o Brasil perdeu competitividade internacional a partir de 1995, resultado da redução da competitividade dos produtos manufaturados básicos (minérios e outros), expressada na queda das exportações em 1990-94, para 0,92\% em 199599. Além dessa perda de competitividade, a economia brasileira passou por uma redução do valor das exportações. As exportações totais reduziram-se de US\$ 53 bilhões, em 1997 , para US\$ 51 bilhões, em 1998, e para US\$ 48 bilhões em 1999. Mas ao mesmo tempo as exportações de produtos agrícolas tiveram um crescimento significante.

Em 1993, o ministro da Economia do governo Itamar Franco, Fernando Henrique Cardoso, implementou um novo programa de estabilização: o Plano Real, feito em três etapas. O Plano Real ancorava-se fundamentalmente em um ajuste fiscal e em um novo sistema de indexação, que levaria progressivamente a uma nova moeda. Conforme Lacerda (2006), ${ }^{4}$ o programa de estabilização do Plano Real consistia no estabelecimento do equilíbrio das contas do governo, objetivando eliminar a principal causa da inflação; na criação de um padrão estável de valor, a Unidade Real de Valor (URV); e finalmente a emissão de uma nova moeda nacional com poder aquisitivo estável, o real.

\section{Fase 1 - O PAI}

A primeira etapa do Real foi implantada com o Programa de Ação Imediata (PAI), em 14 de junho de 1993. Para suprir a necessidade de equilibrar as contas públicas, o governo diagnosticava como necessidades prioritárias a redução dos gastos da União e o aumento da eficiência no ano de 1993, ou seja, redução da participação do governo na economia por meio da privatização das estatais. O Banco Central passou a exercer maior controle sobre

4 LACERDA, A.C., et al.(São Paulo, 2006). os bancos estaduais, além da reestruturação dos bancos federais e estaduais. As privatizações foram necessárias para atingir o equilíbrio financeiro, além de transferir para o setor privado os custos necessários à modernização da infraestrutura, pré-requisito para o desenvolvimento do país. O equilíbrio fiscal era essencial para a estabilização da economia. No entanto, o PAI não impediu a aceleração da economia em 1993, foi então executada a segunda fase do Plano Real, a implementação de uma unidade de conta, a URV.

\section{Fase 2 - A URV}

A URV foi introduzida em 27 de maio de 1994 e serviu como transição para a introdução de uma nova moeda. A URV foi utilizada para restaurar a função de unidade de conta da moeda, que havia sido destruída (LACERDA, 2006). ${ }^{5}$

\section{Fase 3 - A nova moeda}

Uma vez que grande parte dos valores havia sido convertida para a URV, a nova moeda, o REAL, foi introduzida em $1^{\circ}$. de julho de 1994. O Governo absteve-se da utilização de congelamentos, foi adotada uma política monetária restritiva, implicando um limite de curto prazo sobre os empréstimos e exigência de depósito compulsório. Estabeleceu-se um teto máximo na taxa de câmbio, um real equivalia a um dólar. A valorização ocorrida em sua fase inicial foi muito criticada, mas o Plano Real tem sido considerado por diversos analistas um dos mais bem-sucedidos programas de estabilização da história do Brasil.

Os impactos iniciais da introdução do Plano Real foram positivos. A inflação baixou de cerca de $47 \%$ em junho para 0,6\% em dezembro de 1994. O PIB cresceu 5,6\%, em 1994 , e o setor industrial apresentou expansão de $7 \%$. O setor de serviços cresceu $4 \%$, menos que os outros setores. Embora muitos acreditassem que o programa pudesse ser recessivo, a economia manteve-se em expansão nos primeiros três meses de 1995. Nos oito primeiros

LACERDA, A.C., et al.(São Paulo, 2006). 
meses de introdução, o consumo aumentou em média $20 \%$ ao mês.

Segundo Baer (1996), a abertura da economia iniciada pelo Governo Collor/Itamar Franco, e a manutenção de uma taxa de câmbio relativamente estável foram eficientes no controle da estabilidade dos preços durante a introdução do Plano Real. Em 1995, foram criados ajustes que incluíam a desindexação da economia e a tentativa de desacelerar a taxa de crescimento com a finalidade de evitar o ressurgimento da inflação. No final de 1995, com a utilização de medidas de aumentos dos empréstimos compulsórios, restrições de crédito e juros elevados, o Governo optou por sacrificar o crescimento a fim de evitar um déficit muito alto na balança comercial e de reforçar a prevenção contra uma possível inflação de demanda.

Segundo Sayad (1998), a estratégia de utilização da URV no Plano Real permitiu um processo de desindexação da economia, a indexação da URV foi ampliada a quase todos os preços com conversão diária por meio da URV. A fixação da taxa de câmbio acarretou em vários problemas, em razão do excesso de liquidez do dólar no mercado.

A utilização contínua da taxa de câmbio sobrevalorizada, com elevadas taxas de juros praticadas no decorrer do Plano, com o objetivo de controlar a demanda agregada, justificavam-se pelo receio de que uma desvalorização resultaria em pressões inflacionárias. A manutenção de elevadas taxas de juros causou um rápido crescimento da demanda agregada, trazendo alto custo para o Tesouro Nacional. As reduções das tarifas de importação agravaram ainda mais o problema da sobrevalorização cambial. Os juros elevados fizeram que a dívida pública crescesse quase US\$ 70 bilhões, passando de US\$ 30 para US\$ 100 bilhões em julho de 1995. O Plano Real fixou a taxa de câmbio entre dólar e real, permitindo uma entrada maior de dólar nos mercados financeiros, fato conhecido como dolarização.

Sayad (1998) destaca o ponto fraco do Plano Real na utilização da taxa cambial sobrevalorizada. A estabilidade do nível geral de preços depende da estabilidade do câmbio, que por sua vez depende do aumento de exportações, condicionando assim o crescimento da economia brasileira ao crescimento das exportações. Com o aumento de liquidez do dólar no mercado, veio o crescimento do déficit público, tornando a diferença entre os juros domésticos e os juros internacionais o problema mais importante a ser resolvido na questão da estabilização. Os efeitos positivos do Plano Real podem ser analisados em razão da sobrevalorização cambial, que reduziu significativamente os preços dos produtos agrícolas no mercado externo e indiretamente os preços dos produtos no mercado interno representando um aumento do salário real. $\mathrm{O}$ Plano real foi bem-sucedido, porém errou em sobrevalorizar o câmbio, aumentando assim o déficit público. O sucesso da estabilização obtida com o Plano Real dependeu da recuperação da capacidade de crescimento da economia.

Segundo análise de Delfim Netto (1998), ${ }^{6}$ ao se utilizar a âncora cambial, os preços deixaram de crescer, dando fim às hiperinflações. Por meio da introdução da URV, no Plano Real, criou-se um mecanismo capaz de reproduzir as condições de hiperinflação. O fato de não haver utilização da política de congelamento de preços permitiu que a oferta se alinhasse aos preços instantaneamente. Como pontos positivos com a introdução do plano, destacam-se a redução da inflação, uma reestruturação no sistema de crédito, a estabilização dos preços, e um aumento do salário real, a economia brasileira experimentava um momento onde havia uma rápida redução da inflação e uma rápida expansão do produto.

Com a finalidade de manter a estabilidade, o conjunto de políticas adotadas pelo Governo de restrição creditícia, e as altas taxas de juros, resultaram em uma rápida queda no nível dos preços, conduzindo a uma expansão do produto, e depois a uma recessão. 0

DELFIM NETTO, A. O Plano Real e a armadilha do crescimento econômico. In: MERCADANTE. A. (org.). O Brasil Pós-Real: a política econômica em debate, Campinas, UNICAMP, 1998, p.89-100. 
problema de implantação do Plano Real veio à tona quando a restrição do crédito e as altas taxas de juros constituíram-se na armadilha do crescimento da economia. O déficit em contas correntes era ampliado cada vez que a economia retornava ao seu crescimento. A restrição no crédito provocou rapidamente uma drástica restrição no sistema bancário, levando empresas e até os banqueiros à falência, impactando diretamente no aumento do nível de desempregos, causando um grande desequilíbrio no processo produtivo. Os gastos com juros passaram de $R \$ 23$ ou $R \$ 24$ bilhões, em 1995, para R\$38 bilhões em 1996. O déficit em contas correntes não era o único empecilho ao crescimento econômico, a carência de investimentos em infraestrutura era outro fator que causava esse empecilho.

Muitos autores divergem opiniões atribuídas ao resultado final do Plano Real, mas concordam que o problema principal foi a utilização da taxa cambial sobrevalorizada. No período de 1974/94, a inflação brasileira apresentou taxas crescentes, porém tendo sida interrompida por momentos curtos durante implantações de vários planos de estabilização, o fracasso dos planos anteriores tornava o sucesso do Plano Real indubitável.

\section{CONSIDERAÇÕES FINAIS}

O crescimento acelerado pelo qual passou a economia brasileira, nos anos 1970, marcado principalmente pelo processo de substituição de importações, não pôde ser visto ao longo dos anos 1980. As políticas econômicas adotadas durante o "Milagre Econômico" sucederam em importantes mudanças estruturais na economia, além de possibilitarem altas taxas de crescimento do PIB e elevado crescimento de exportações das mercadorias entre outros fatores.

No período de 1980-1990, o país atravessou um longo tempo de estagnação, com al- tos índices de inflação, retração da produção industrial, aumento do endividamento externo, endividamento do setor público, déficit no balanço de pagamentos, altos níveis de desemprego e problemas de desigualdade socioeconômica. A profunda crise econômica pela qual ficaram marcados os anos 1980 evidencia uma série de problemas oriundos do "Milagre", conforme analisados neste trabalho. O período de 1980-1990 teve grande importância devido às transformações ocorridas, com sérias consequências tanto sociais quanto econômicas para o país. As políticas e medidas adotadas pelo Governo na época não contribuíram para uma melhora da crise, levando a economia a retroceder cada vez mais. Podendo se destacar como principais causas o aumento da dívida eterna, a excessiva proteção à indústria nacional, o fracasso dos programas de estabilização no combate à inflação e o desgaste de um modelo de desenvolvimento ancorado na intervenção do Estado na economia.

Após inúmeras frustrações e tentativas de estabelecer o equilíbrio econômico ao longo dos anos 1980-1990, o Plano Real foi o mais bem-sucedido em seu objetivo primordial: conter os desequilíbrios inflacionários. Apenas em 1994, com a implementação do Plano Real, foi possível atingir a estabilidade inflacionária e o restabelecimento do controle sobre as finanças públicas do País. Diferindo dos outros planos, o câmbio valorizado e taxas de juros elevadas foram as principais características do Plano Real, que propunha mudanças nos regimes fiscais e monetários.

Conforme observado neste trabalho, os efeitos iniciais do Plano Real foram positivos, a inflação retrocedeu de $47 \%$ em junho para 0,6\% em dezembro de 1994, e o PIB cresceu 5,6\% em 1994. O Sucesso do Plano Real pôs fim a décadas de inflação elevada, desencadeando, contudo, sérias consequências para o país. 


\section{REFERÊNCIAS}

AVERBUG, M. "Plano Cruzado: Crônica de uma Experiência." Revista do BNDES, Rio de Janeiro, V.12, n.24, p. 211-240, dez., 2005.

BAER, W. A Economia Brasileira. São Paulo: Nobel, 1996.

BAER, W. “A Retomada da Inflação no Brasil: 1974-1986.” Revista de Economia Política, São Paulo, v.7, n.1, p. 29-72, jan./mar., 1987.

BELLUZZO, L. G. M.; ALMEIDA, J. S. G. "Crise e reforma monetária no Brasil." São Paulo em Perspectiva, São Paulo, v.4, n.1, p. 63-75, jan./mar., 1990.

BRESSER PEREIRA, L. C.; NAKANO, Y. "Hiperinflação e estabilização no Brasil: o Primeiro Plano Collor.” Revista de Economia Política, São Paulo, v. 11, n. 4(44), p. 89-114, out./dez., 1991.

CARNEIRO, R. Desenvolvimento em Crise: a economia brasileira no último quarto do século XX, 1.ed. São Paulo: UNESP, IE-UNICAMP, 2002.

COUTINHO, L.; FERRAZ, J.C. (Coord.). Estudo da competitividade da indústria brasileira, 2.ed. Campinas: UNICAMP,1993.

FURTADO, C. Formação Econômica do Brasil, 34. ed. São Paulo: Companhia das Letras, 2007.

GONÇALVES, R. "Comércio externo, investimento externo e emprego - resenha." Desenvolvimento humano e trabalho decente: a experiência brasileira recente, Cepal-PNUD-OIT, 2008. Disponível em: <www.cepal.org/brasil>.

GONÇALVES, R. O Brasil e o comércio internacional - transformações e perspectivas. São Paulo: Contexto, 2000.

LACERDA, A.C., et al. Economia brasileira. 4.ed. São Paulo: Saraiva, 2006.

. O Impacto da Globalização na Economia Brasileira. São Paulo: Contexto, 1998.

MERCADANTE, A., et al. O Brasil pós-Real: a política econômica em Debate. Campinas: UNICAMP, 1998.

SANTOS, F.S.; SANTOS, A.L.A.; SANTOS, M.G.L. “A Economia Brasileira no período de 19801990: A Década Perdida?” Hist. do Pensamento Econômico e Econ. Bras., ago./2013, Disponível em: <http://www.paece.com.br/semanaeconomista2013>, 2013.

SAYAD, J. “Observações sobre o Plano Real.” Estudos Econômicos, São Paulo, v. 25, n. especial, p. 7-24, $1995 / 96$.

VELOSO, F. A.; VILLELA, A.; GIAMBIAGI, F. Determinantes do "milagre" econômico brasileiro (1968-1973): uma análise empírica. Rev. Bras. Econ., Rio de Janeiro, v.62, n.2, abr./jun., 2008.

\section{Dados da Autora}

Graduada em Ciências Econômicas pela Universidade Metodista de Piracicaba - UNIMEP em 2015. Piracicaba/SP - Brasil.mnmartins@live.com

Submetido em: 14-9-2016

Aceito em: 30-1-2017 